Revista Aspas

ppgac - USP

Artigo

\title{
GEOMETRIAS DO CORPO: ENTRE O BUTÔ E A ARQUITETURA
}

\author{
BODY GEOMETRIES: BETWEEN BUTOH AND ARCHITECTURE
}

\section{LAS GEOMETRIAS DEL CUERPO: ENTRE EL BUTOH Y LA ARQUITECTURA}

\section{lan Habib e André Vaillant}

Ian Habib

Mestre em Dança pela Universidade Federal da Bahia (Corpos

Transformacionais, 2020). Sob orientação de Dr. Fernando

Marques Camargo Ferraz. CAPES (CNPQ). Artista cênico, dançarino e pesquisador transgênero. Investiga Dança Butô e

Performance, com ênfase nas poéticas das transformações corporais e alterações de estados corporais.

André Vaillant

Arquiteto graduado pela Pontifícia Universidade Católica de

Minas Gerais e pelo Institute for Housing and Urban Development Studies da Universidade de Rotterdam (Países

Baixos). Atuou como pesquisador voluntário nos grupos de pesquisa Cosmópolis (UFMG) e Estética e Materialidade (PUCMG). Viveu e trabalhou na Índia e na Hungria. 


\section{Resumo}

Este artigo propõe um contraponto entre as noções de corpo e espacialidade desenvolvidas tradicionalmente na arquitetura e no urbanismo e aquelas da dança, em particular o Butô. Para tanto, são brevemente analisadas as formas de representação, a morfologia e a história da arquitetura clássica e os conceitos de corpoespaço e espaçotempo na dança de Min Tanaka e no Butô. Dessa comparação pretende-se depreender novas possibilidades de percepção e interação entre espaço e corpo na coreografia e no projeto arquitetônico.

Palavras-chave: arquitetura, butô, espaço, corpo, representação

\section{Abstract}

This article aims to develop a counterpoint between the notions of body and spatiality traditionally present in architecture and urban planning and those observed in dance, in particular Butoh ballet. On this purpose, we analyze the representation forms, the morphology and history of classical architecture and the concepts of bodyspace and spacetime in the work of Min Tanaka and in Butoh dance in general. From this comparison, we intend to understand new perception possibilities and interaction between space and body in choreography and architectural planning.

Key words: architecture, butoh, space, body, representation

\section{Español}

Este artículo propone un contrapunto entre las nociones de cuerpo y espacialidad tradicionalmente desarrolladas en arquitectura y urbanismo y las de danza, en particular Butoh. Para esto, se analizan brevemente las formas de representación, la morfología e historia de la arquitectura clásica y los conceptos de espaciocuerpo y espaciotiempo en la danza de Min Tanaka y en el ballet Butoh. A partir de esta comparación, pretendemos comprender nuevas posibilidades de percepción e interacción entre el espacio y el cuerpo en la coreografía y en el diseño arquitectónico.

Palabras clave: arquitectura, butoh, espacio, cuerpo, representación 


\section{Espaço feito corpo}

A história das cidades parece, pelo menos desde a antiguidade clássica, entretecida com aquela de uma analogia - entre o homem e a cidade, o produto e seu fazedor. Não à toa, à teoria esboçada no livro II da República já se chamou "teoria orgânica”, "(...) em que se vê no Estado uma pessoa política, dotada de vida e caráter próprios" (PEREIRA, 2001, p. XLV). Também ao longo dos demais livros abundam analogias entre o corpo e a polis, a medicina e o governo (no livro I, 342d, por exemplo; no II, 369d; etc). Da cidade grega, Cauquelin (2005) nos dirá que "O lugar é um território a que estamos ancorados por nascimento (...) Tenho meus antepassados, é uma terra onde estão meus mortos" (p. 107). Para o grego, o pertencimento à polis (cidadania) estava também associado ao pertencimento físico à terra pelo sepultamento dos mortos, em que relações corpóreas de parentesco e presença se estabelecem para formar o cidadão. A autora vai além:

\footnotetext{
Porque no momento de nascimento da democracia, que substitui as realezas arcaicas, o espaço e o tempo são redefinidos. Uma geometrização do território, paralela ao avanço das matemáticas, permite medir e, portanto, comparar entre si as porções de território assim limitadas e avaliadas. (...) Dito de um outro modo, assim se forma o território - lugar tornado espaço - econômico e político. (...) O lugar está onde o encontramos, onde o ativamos. E de incorpóreo que era, ele se torna um corpo. (idem, p. 108-111).
}

Essa passagem de um lugar indeterminado a um espaço medido e mediado, precisado matematicamente e governado por leis que pressupõem e normatizam trocas, é a fundação de uma cidade. E é também a passagem de um espaço anterior a um espaço "corpóreo", como diz a autora, graças também a uma geometrização (arquitetura). Estabelece-se, portanto, desde a definição grega de cidade, uma relação intrínseca entre a geometria construtiva e a fisiologia humana. Sennet, a esse respeito, escreve: "Os atenienses faziam uma analogia direta entre corpo e construção; não que eles erguessem prédios no formato humano, de cabeças e dedos. Mais que isso, valiam-se do seu entendimento fisiológico para criar formas urbanas." (2003, p. 45). 
O exemplo mais comum é o Parthenon, em que o edifício segue as proporções do corpo monumental da deusa Atena, de doze metros de altura, que abrigava. O mesmo se dará entre os romanos, posteriormente, e de maneira mais direta, pois que Vitrúvio se ocupará de explicitá-lo. Segundo Sennet, "Vitrúvio relaciona as disposições regulares do corpo às que a arquitetura do templo deve obedecer" (2003, p. 95). Mas não somente: para os romanos, o edifício deve manter a simetria bilateral organizando em pares opostos de lados as mesmas disposições e frações.

\begin{abstract}
Vitrúvio imaginava que os braços eram ligados às pernas pelo umbigo, isto é, pelo cordão umbilical - a fonte da vida -, ponto de encontro das linhas que partiam dos braços estendidos e cuja interseção se situava na ponta dos dedos, formando um quadrado. (...) Baseados nela, seus princípios moldaram o interior do Pantheon, onde o quadrado estava inscrito dentro do círculo, e inspiraram, séculos depois, os desenhos de Leonardo e Serlio. (SENNET, 2003 p. 95).
\end{abstract}

Aqui vale determo-nos sobre esta tradição nascente, ou seja, aquela de desenhos geométricos do corpo humano baseados em proporções senão ideais, pelo menos teóricas, apreendidas por uma certa fisiologia. Artistas como Dürer, Fludd e Cesariano, além daqueles mencionados por Sennet, tentaram ilustrar o homem segundo a descrição do arquiteto. Nessa tradição, porém, o que prepondera não é o corpo, mas a geometria. Tomemos o exemplo de Ryff (FIGURA 1), em que a rigidez desconfortável e o estiramento quase desproporcional do corpo são flagrantes. 
Figura 1: Proportionen einer Figur. Walther Hermann Ryff, 1547.

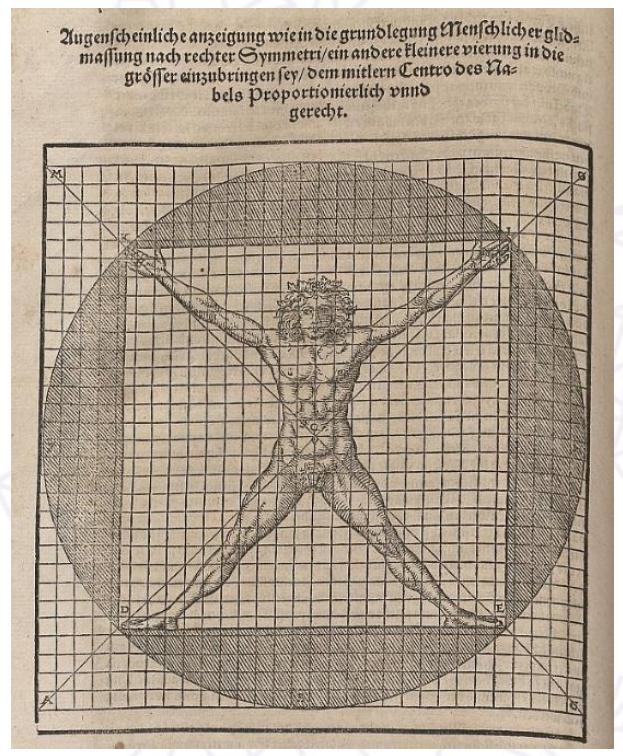

Fonte: Deutsche Fotothek

O que fica evidente é que na correspondência entre Roma e seus herdeiros renascentistas, observa-se a passagem de uma analogia a uma geometria propriamente dita: passamos a ter uma tradição de estudos matemáticos de desenho do corpo humano, de apreensão de sua forma baseada em princípios lógicos, e de suas proporções a partir de frações e correspondências bidimensionais. Essa técnica, porém, não pertence à esfera do retrato, mas da arquitetura. O corpo, aqui, não se desenha visando a caracterização do indivíduo, mas aquela do espaço - e fica evidente, também, a noção já então presente de que, em virtude da percepção, é o espaço que emana do corpo. Não por acaso, na mesma época e por processos semelhantes, se desenvolveu a perspectiva como um desdobramento das emanações desses corpos geometrizados. Quando observamos, por exemplo, os esquemas da percepção visual de Brunelleschi, ou as xilogravuras de Dürer acerca das projeções cônicas, fica evidente a correlação. Ambos envolvem a centralidade do olho no espaço ou as relações entre distâncias em relação ao observador.

\footnotetext{
${ }^{1}$ Disponível em: <https://bit.ly/3bJQ0DP>. Acessado em Maio de 2020.
} 
O que fica claro entre a perspectiva e a geometrização do corpo humano é que essas duas categorias, corpo e espaço, se apreendem uma pela outra. É o corpo que produz espaço. Nesse sentido, Merleau-Ponty concluirá: “(...) nosso corpo não é apenas um espaço expressivo entre todos os outros. (...) Ele é a origem de todos os outros" (2018, p. 202). Talvez por isso a tradição de depreender geometrias da forma humana pôde seguir modernidade adentro e constituir-se como uma técnica projetual propriamente dita. Seria na modernidade, com o racionalismo e o advento de novas técnicas de representação (artísticas e matemáticas) que uma passagem se efetuaria dos antigos tratados de arquitetura para os manuais modernos. São exemplos "A arte de projetar em arquitetura", de Neufert (FIGURA 2), de 1936, e "O Modulor" (FIGURA 3), de Corbusier, 1948.

Figura 2: Der Mensch: das mass aller Dinge. Neufert, 1936.

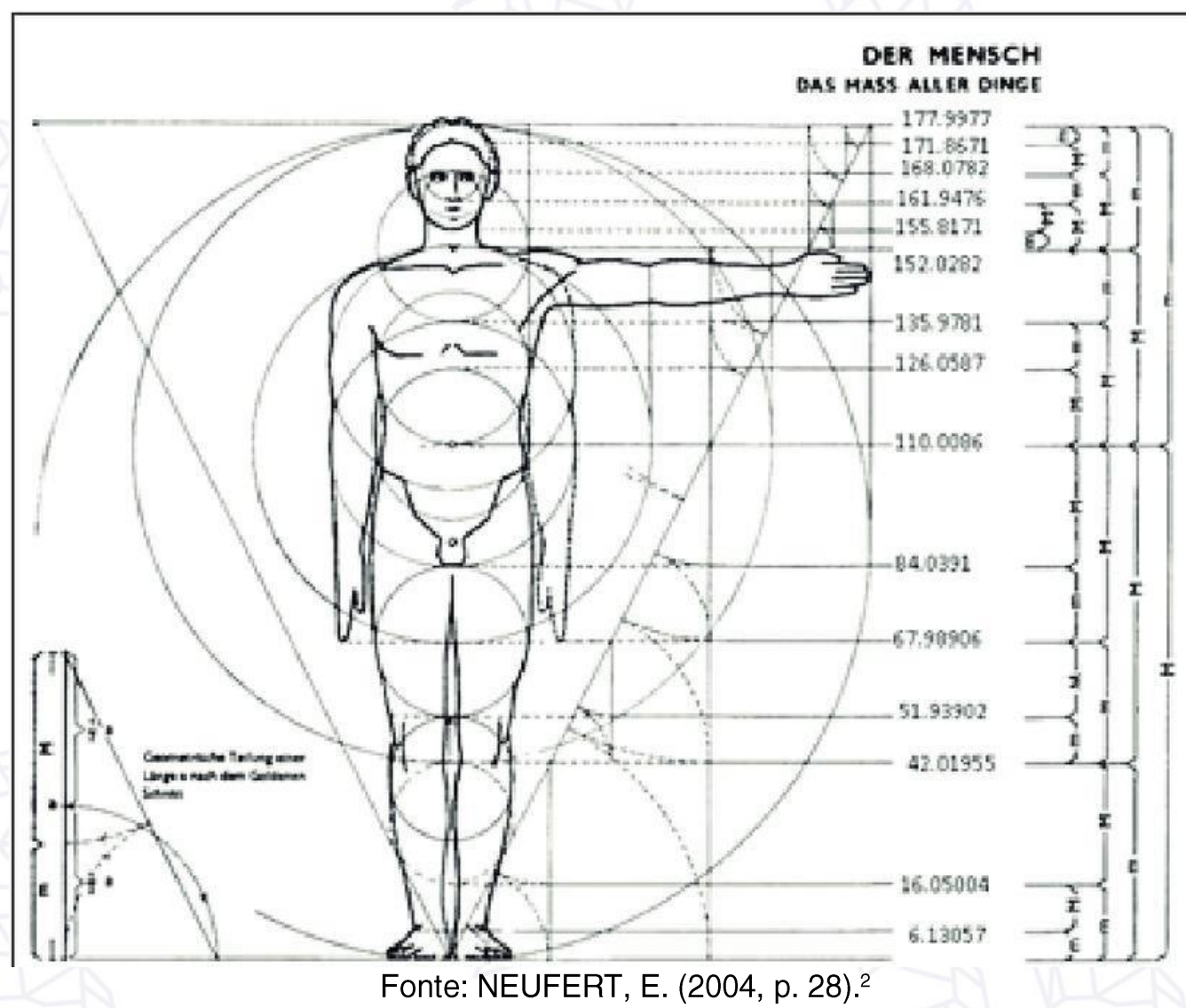

${ }^{2}$ NEUFERT, E. Arte de projetar em arquitetura. 17. ed., Barcelona: Gustavo Gili, 2004. 
Figura 3: O Modulor. Le Corbusier, 1948.

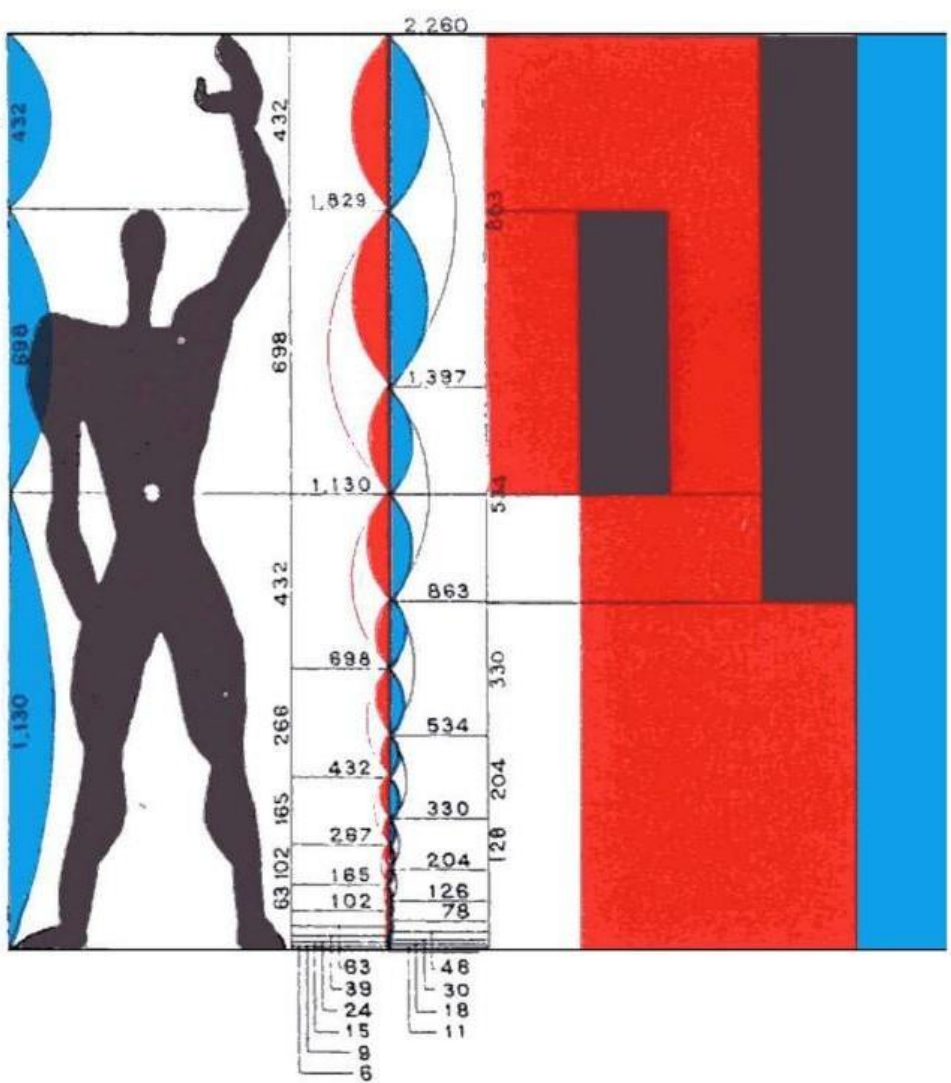

Fonte: Fondation Le Corbusier ${ }^{3}$

A figura humana, aqui, aparece muito mais abstrata que seus correspondentes renascentistas. Plenamente geometrizada, não está mais simplesmente inscrita a uma ou outra forma, mas está também completamente mapeada em suas medidas e correlações. Duas coisas saltam aos olhos nessas imagens: a rigidez dessas figuras e sua impossibilidade orgânica. Muitos versaram sobre os métodos de depreensão dessas figuras; Neufert, por exemplo, teria se baseado nas médias aritméticas das medidas humanas. Aqui fala-se no caráter fortemente eugenista desses esquemas, que se referem às medidas depreendidas entre somente alguns grupos étnicos e sociais. Para além disso, cabe também o contraponto óbvio de que a média aritmética de uma série de valores não necessariamente corresponde a nenhum deles, e por vezes nada mais é que uma abstração matemática generalizante da sequência. Ou seja, corpos que não existem, que são somente espaço apreendido, espaço feito corpo.

\footnotetext{
${ }^{3}$ Disponível em: <https://bit.ly/3bONPhX $>$. Acessado em Maio de 2020.
} 


\section{Além da forma inscrita}

Na primeira parte da Fenomenologia da Percepção, Ponty se debruça sobre as correlações entre movimento, linguagem e percepção. $O$ autor aponta a existência de um sentido atribuído ao movimento, através do qual se percebe reciprocamente corpo e espaço. O que fica claro é que não há percepção sem movimento - Ponty diz: “(...) esses esclarecimentos nos permitem compreender sem equívoco a motricidade enquanto intencionalidade original. Originalmente a consciência não é um "eu penso que", mas um "eu posso" (2018, p. 192). O próprio título dessa seção é sugestivo ${ }^{4}$. De fato, o que observamos na história da arquitetura em sua relação com o corpo é que esse corpo, bem projetado e mapeado, só é capaz de movimentos mecânicos, de repetição controlada pelas relações geométricas que o inscrevem. Seus pés só pisam onde os vértices do quadrado circunscrito indicam. Citamos ainda uma vez Ponty:

O corpo é nosso meio geral de ter um mundo. Ora ele se limita aos gestos necessários à conservação da vida e, correlativamente, põe em torno de nós um mundo biológico; ora, brincando com seus primeiros gestos e passando de seu sentido próprio a um sentido figurado, ele manifesta através deles um novo núcleo de significação: é o caso dos hábitos motores como a dança. (2018, p. 203).

Será na dança que outras formas de apreensão do corpo no espaço se desenvolverão paralelamente. O espaço do corpo em movimento foi concebido, por exemplo, em Laban (1971), pela figura do icosaedro, uma forma geométrica de vinte faces que marcam todas as direções e planos possíveis de movimento corporal. Nessa grande categoria de pensamento das relações corpo-espaciais estão inclusas as live arts da década de 1960 e do início da década de 1970, que "exigiam uma reconsideração de onde a arte pode ser colocada e executada" (HUNTER, 2015, p. 4).

\footnotetext{
${ }^{4}$ Trata-se de "O corpo como objeto e a fisiologia mecanicista".
} 
Os anos sessenta e setenta, segundo a historiadora Sally Banes (2015), enfatizaram politicamente a liberdade e a comunidade. Anna Halprin, Barbara Dilley e Simoni Forti, por exemplo, dedicaram-se ao que a autora chamou de "coreografia indeterminada", "coreografia aberta" ou "composição responsiva-situacional" (BANES, 2015, p. 135), modalidades que focaram nos processos subjetivos de tomada de decisão. Na mesma época, o coreógrafo Merce Cunningham desafiou noções euclidianas de espaço, "adotando o mantra de Einstein de "não há pontos fixos" (HUNTER, 2015, p. 8). Essa proposta modificou as práticas de posicionamento do público em novas relações entre público-intérprete, e as escolhas do local da performance. A questão, aqui, é que o movimento produz suas lógicas próprias, inclusive físicas, de tempo e espaço. Ponty dirá:

Enquanto tenho um corpo e através dele ajo no mundo, para mim o espaço e o tempo não são uma soma de pontos justapostos, nem tampouco uma infinidade de relações das quais minha consciência operaria a síntese e em que ela implicaria meu corpo; não estou no espaço e no tempo, não penso o espaço e o tempo; eu sou no espaço e no tempo, meu corpo aplica-se a eles e os abarca. (2008, p. 194-195).

Na atividade do Grand Union, por exemplo - um grupo de improvisação em dança integrado, dentre outros, por Steve Paxton e Trisha Brown -, vemos o espaço se tornar local ativo de experimentação (BANES, 2015), em que qualquer coisa pode ser imaginada e testada. Os primeiros trabalhos de Trisha Brown envolveram a descida e a subida de fachadas de grandes edifícios, apresentações íntimas em casas privadas e dança em telhados, em investigações de reversão das relações entre verticalidade e horizontalidade. Por fim se pode falar, talvez, em uma culminância na dissolução desses limites na dança Butô, em que o corpo é o próprio ambiente, naquilo que expressa Min Tanaka:

Qual é o meu ponto de limiar? O que significa ser dançarino em um palco público? Tudo está ficando vago. Mas só porque estou constantemente levando em consideração que estou superando um limiar, isso é uma iniciativa cartográfica, uma tentativa de me localizar em um ambiente? Ou estou percebendo que sou um ambiente como tal? (TANAKA apud GUATTARI, 2015, p. 46). 


\title{
3. Através do corpoespaço
}

Eu não danço no espaço, mas eu sou o espaço. ${ }^{5}$

Waguri (apud LIAO, 2006, p. 66) afirma que Hijikata utilizou nikutai para descrever o corpo que dança e karada para presentificar o corpo vazio, cremado, que pode ser atravessado pela natureza de forma a apresentá-la. Esse é um dos propósitos da dança de Min Tanaka - que pode ser pensada através das múltiplas conexões que o dançarino faz com o Butô -, em que um corpo vazio, ou seja, um corpo que se transforma no ato de cremação, pode se encontrar e se fundir com um espaço, ou seja, ser o próprio espaço. 0 corpo vazio:

\begin{abstract}
Tem sido usado para descrever uma instância particular em relação ao corpo dançante. Durante o desenvolvimento da dança Butô, a noção do corpo vazio foi explicada a partir de diferentes perspectivas e considerada a partir do uso de uma variedade de termos. Dois termos que foram utilizados no final dos anos 1950 são nikutai e karada. O termo nikutai começou a ser usado durante o período Meiji para significar um corpo que é recheado e embalado firmemente. Karada foi usado após a Segunda Guerra Mundial para designar um corpo que está vazio. O termo kara implica "vazio" e da implica "em pé". (LIAO, 2016, p. 59 e 60, tradução nossa, grifos nossos).
\end{abstract}

Se essa é a única forma de dançar em que as fronteiras entre corpo e espaço se esvaem completamente, chamaremos a essa tessitura, que adquire ao longo do tempo diversos estados, de corpoespaço. Esse corpoespaço cremado desdobrou-se na concepção de bodyweather (corpoclima), de Min Tanaka, como a criação de um corpo que, segundo o dançarino, "lida com a paisagem, o corpo em relação ao clima"6. Tanaka criou sua dança de acordo com método destinado a pensar as transformações de estados que ocorrem simultaneamente no espaço, isto é, em uma configuração concebida como paisagem cujo clima transforma-se incessantemente, e no corpo. Dessa forma há, então, corpoespaço como uma só instância. Pois que, se o corpo transforma o espaço e concomitantemente

\footnotetext{
${ }^{5}$ TANAKA apud VIALA E MASSON-SEKINE, 1988, p. 158.

${ }^{6}$ Disponível em: <https://bit.ly/3g6rmkg>. Acesso em: 12 maio 2020.
} 
é transformado por ele, corpoespaço não são descontínuos, corporificandose mutuamente. $\mathrm{O}$ corpo é clima e é ambiente, corpoclima/corpopaisagem, por estar em constante transformação relacional e complexa de estados.

A chácara de Hakushu é onde Tanaka investiga o conceito, criado em 1977, de Body Weather Farm, em um laboratório de pesquisa em dança fundado em 1978. A proposta do dançarino é uma forma única de viver, trabalhar e criar em comunidade, onde "detalhes geográficos físicos são experienciados com intimidade, como uma extensão do corpo."7. Ser o espaço na dança é, então, dançar trabalhando nos campos e cultivando alimentos e animais, e é esse processo que infiltra corpo em paisagem/paisagem em corpo. $\mathrm{O}$ artista chama a atenção da conexão entre o nascimento da dança e as atividades ocorridas no espaço, que, em quase todas as culturas e civilizações, apontavam para a vida agrícola:

O trabalho agrícola, no sentido criativo, está intimamente ligado à dança. Que nosso corpo seja exposto ao ambiente externo, ao vento, luz, calor (...) como fazendeiros, pensávamos que nosso corpo vibraria ou se chocaria com esses fenômenos, ou estaria em harmonia com eles profundamente dentro de nós. A dança surgiu através de tais relações, imaginamos ${ }^{8}$.

Ser um ambiente como tal depende, então, das relações entre os estados corpoespaciais. A relacionalidade pode ser presumida no que Tanaka chama de "eu" como uma forma sem conteúdo, uma ontologia de omni-centralidade relacional, que possibilita que o corpo esvaziado tenha seu centro em todos os espaços, isto é, seja o todo:

Simplificando, Body Weather é uma noção de omni-centralidade. Contingência também. "Eu" não é o centro. O centro é todo lugar. Fazer algo entre uma pessoa e outra. "Eu sou..." nem sempre vem em primeiro lugar. Pode ser, é uma noção viável. Mas ser identificado com outra pessoa ou outra coisa talvez seja deriva. Isso é verdade sobre as relações humanas, fenômenos meteorológicos, sol, animais e quase tudo ao nosso redor. Um clima como um relacionamento contingente e em constante mudança. ${ }^{9}$

\footnotetext{
${ }^{7}$ Disponível em: <https://bit.ly/3g6rmkg>. Acesso em: 12 maio 2020.

${ }^{8}$ Disponível em: $<$ https://bit.ly/3cQYnil $>$. Acesso em: 12 maio 2020.

${ }^{9}$ Idem.
} 
Aqui é importante lembrar que, para Tanaka, a unidade mínima é dois (apud QUINCEY, 2003, p. 3); deriva-se que as relações corpoespaciais se dão no tempo, já que "a dança emerge no tempo e espaço, e é algo que se persegue infindavelmente."'10. Portanto, o corpoespaço é também um espaçotempo, já que os dançarinos do Butô provocam fissuras nas separações entre o espaço e o tempo, contribuindo para um rompimento subversivo na dualidade objetivo/subjetivo. Para Pilgrim (1995), a experiência do ambiente acontece perceptivamente $e$ inerentemente aos eventosfenômenos que nele ocorrem. O autor interliga o espaçotempo a ma, palavra rica em significados e ambiguidade, e que significa "entre", e está presente no Japão como um paradigma estético-religioso, inclusive nas projeções espaciais arquitetônicas:

\begin{abstract}
A palavra ma basicamente significa um "intervalo" entre duas (ou mais) coisas e eventos espaciais ou temporais. Portanto, não é apenas usada em composições para sugerir medidas, mas carrega significados como intervalo, abertura, espaço entre, tempo entre e assim por diante. Uma sala é chamada ma, por exemplo, enquanto se refere ao espaço entre as paredes; um descanso na música também é a pausa entre as notas ou os sons. (...) Assim sendo, a palavra ma claramente começa a ter um significado relacional (PILGRIM, 1995, p. 255 e 256, tradução nossa).
\end{abstract}

O espaçotempo é, dessa forma, importante chave de análise para pensar o corpoespaço, pois indica uma dança que é feita no entre, já que o que conta não é a imagem, "mas o que se passa entre as imagens. Também não é o movimento ou os movimentos. É o próprio tempo" (UNO, 2012, p. 57).

\title{
5. À guisa de conclusão
}

O espaço emana do corpo e se volta sobre ele; espaço e corpo se produzem mutuamente. O que medeia essas relações é uma terceira estância, ou seja, a linguagem - aqui também chamada "representação". Tratada entre motricidade e percepção já na fenomenologia de Ponty, a linguagem é o que permite a apreensão e a projeção, que faz a passagem

${ }^{10}$ Disponível em: <https://bit.ly/2LJ2bpQ>. Acesso em: 12 maio 2020. 
entre movimento e dança, espaço e arquitetura. Nesse sentido, uma primeira conclusão que se pode depreender é que há um descompasso entre a realidade orgânica do ser humano e aquela do projeto de arquitetura. Que os corpos tomados como decalques geométricos produzem somente espaços euclidianos de pouca fluidez e grande imobilidade. Não pressupõem percepções outras, processuais e participativas, do espaço.

Esse questionamento parece presente nas propostas de diversos artistas e performers sobretudo a partir da década de 60. Na dança, onde a apreensão do corpo se deu pelo movimento, levantamos diversos experimentos de apreensões alternativas da relação corpo-espaço que culminam no Butô. Proponente de uma terceira ou quarta dimensão (corpoespaço) dessa relação, em que esses limites se fundem, no butô não se trata mais de uma dinâmica dual entre forma e invólucro, mas envolvimentos mútuos.

O que se convida, aqui, a pensar, são as consequências para a arquitetura e para a dança de se encarar essas experiências dos bailarinos e artistas performáticos no espaço, diante das quais o projeto em eixos ortogonais parece inevitavelmente antiquado. Formas de registro do corpo em movimento geram não somente retratos processuais de suas ações originárias, como também objetos espaciais e meios de representação que a arquitetura frequentemente ignora. Considerando-se os diversos suportes possíveis e recursos de registro, desenvolvimento e projeção em desenho, pintura, dança e performance, parece urgente se pensar em novas formas de se abordar o projeto e a coreografia em arquitetura e dança, que extrapolem as dualidades tradicionais entre sujeito-espaço, cognoscível e cognoscente, por relações de entretecimento e participação.

\section{Agradecimento}

Agradecemos à Raquel Bambirra pela leitura cuidadosa e revisão deste texto. 


\section{Referências bibliográficas}

BANES, S. Spontaneous combustion: Notes on dance improvisation from the sixties to the nineties. In: CAINES, R.; HEBLEY, A. (Eds.). The improvisation studies reader: Spontaneous acts. New York: Routledge, 2015. p. 135-141.

CAUQUELIN, A. Sítio, lugar e mundo. In: VAZ-PINHEIRO, G. (Org.) Curadoria do local. Torres Vedras: ArtlnSite, 2005.

GUATTARI, F. Machinic Eros: Writings on Japan. GENOSKO, G.; HETRICK, J. (Eds.). Minneapolis: Univocal Publishing, 2015.

HUNTER, V. Introduction. In: HUNTER, V. (Ed.). Moving sites: Investigating sitespecific dance performance. New York: Routledge, 2015. p. 1-22.

LABAN, R. Domínio do corpo. São Paulo: Summus, 1971.

LIAO, P. An inquiry into the creative process of Butoh: With reference to the implications of eastern and western significances. Tese (Doutorado) - City

University of London, Londres, 2006.

MERLEAU-PONTY, M. Fenomenologia da percepção. Trad. Carlos Alberto Ribeiro de Moura. 5. ed. São Paulo: Martins Fontes, 2018.

NEUFERT, E. A arte de projetar em arquitetura. Trad. Benelisa Franco. 35. ed. Barcelona: Gustavo Gili, 2004.

PEREIRA, M. H. Introdução. In: PLATÃO. A República. Trad. Maria Helena da Rocha Pereira. Lisboa: Fundação Calouste Gulbenkian, 2001. p. V-LX.

PILGRIM, R. Intervals ( $M a)$ in space and time: Foundations for a religio-aesthetic paradigm in Japan. History of Religions, Chicago, v. 25, n. 3, p. 255-277, fev. 1986. PLATÃO. A República. Trad. Maria Helena da Rocha Pereira. Lisboa: Fundação Calouste Gulbenkian, 2001.

QUINCEY, T. Sites of multiplicity \& permeation. Disponível em:

$<$ https://bit.ly/3bMpqdu>. Acesso em: 12 maio 2020.

SENNET, R. Carne e pedra: O corpo e a cidade na civilização ocidental. Trad. Marcos Arão Reis. 3. ed. Rio de Janeiro: Record, 2003.

UNO, K. A gênese de um corpo desconhecido. São Paulo: n-1 edições, 2012.

VIALA, J; MASSON-SEKINE, N. Butoh: Shades of darkness. 1. ed. Tokyo:

Shufunotomo, 1988. 